\title{
Concurrent administration of methanolic extract of Zingiber officinale Roscoe (Zingiberales: Zingiberaceae) and diminazene aceturate enhanced survival rate and reduced parasitaemia in experimental murine Trypanosoma brucei Plimmer \& Bradford, 1899 (Kinetoplastea: Trypanosomatida) infection
}

\section{K. Anya and K. I. Eghianruwa*}

Department of Veterinary Pharmacology and Toxicolgy. University of Ibadan. Nigeria. *Email: keghianruwa@gmail.com.

\begin{abstract}
The efficacy of concurrent diminazene and Zingiber officinale Roscoe (Zingiberales: Zingiberaceae) extract in murine Trypanosoma brucei Plimmer \& Bradford, 1899 (Kinetoplastea: Trypanosomatida) infection was evaluated. Two infected groups were treated with extract at $400 \mathrm{mg} \cdot \mathrm{kg}^{-1}$ (G1) and $800 \mathrm{mg} \cdot \mathrm{kg}^{-1}$ (G2) alone while another two groups received 400 mg.kg-1 (GD1) and 800 mg.kg- ${ }^{-1}$ (GD2) of extract concurrently with diminazene $3.5 \mathrm{mg} \cdot \mathrm{kg}^{-1}$ intraperitoneally. One infected group received diminazene $3.5 \mathrm{mg} . \mathrm{kg}^{-1}$ only (D) while another received 1 mg.kg-1 Tween 80 (C1) orally. The seventh group was uninfected and untreated (C2). Survival rate, parasitemia, liver weight, spleen weight, haematological indices were evaluated. Survival rates were $0 \%$ in C1, G1 and G2, 20\% in D, 40\% in GD2, $60 \%$ in GD1 and 100\% in C2. Animals in groups G1, G2 and C1 died between 6 and 8 days pt. Parasitemia levels were significantly $(\mathrm{P}<0.05)$ higher in D1 than in GD1 and GD2 by day 16 post treatment. PCV and RBC counts were significantly $(\mathrm{P}<0.05)$ lower in GD1, GD2 and D than in C2. Liver and spleen weights increased significantly $(\mathrm{P}<0.05)$ due to infection and never fully recovered in all treatment options. Ginger (Z. officinale) extract enhanced diminazene efficacy by increasing survival rates and lowering parasitemia.
\end{abstract}

Keywords: Diminazene; Ginger; Trypanosome; Survivability; Parasitemia; Haematology; Murine.
Received

January 05, 2018

Accepted

April 12, 2018

Released

April 30, 2018

Full Text Article

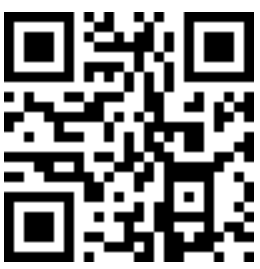

ORCID

D) $0000-0002-8255-2831$

D. K. Anya

(ㄱ) 0000-0002-5440-0486

K. I. Eghianruwa

\section{Introduction}

The scourge of African Animal Trypanosomosis (AAT), a disease complex (Onyiah, 1997) which has largely be responsible for poor livestock production in endemic areas like Nigeria (ILRI, 2008), is a continual problem for which no adequate control measures exist in spite of the efforts and resources 
expended on its study. Currently, the major means of controlling the disease relies on the use of few aged trypanocides which cause severe toxicity and to which parasite resistance is widespread. The impetus to develop new drugs is not high when one considers the cost of developing new drugs vis-a-vis the economic power of the countries where trypanosomosis is endemic. However, efforts have been made by several researchers to elucidate how these old trypanocides can be made to perform better in the absence of new drugs. Several measures have been adopted. One of these is the administration of a trypanocide concurrently with antioxidants. Results from studies on the combination of antioxidants with diminazene strongly suggest that diminazene efficacy is enhanced when combined with antioxidants (Eghianruwa et al., 2009; Eghianruwa and Anika, 2010). It has also been reported that methanolic extract of Azadirachta indica enhanced the efficacy of dimiunazene (Omoja et al., 2011).

Reports of plants with antitrypanosomal actions abound in literature (Adeiza et al., 2010; Ogbadoyi et al., 2011; Omoga et al., 2011; Kobo et al., 2014). Nigeria's rich biodiversity endows her with potentials of medicinal plants against several diseases. Therefore resorting to nature for control of the constant threat of trypanosomosis outbreak may be prudent.

The rhizome of Zingiber officinale Roscoe (Zingiberales: Zingiberaceae), often called ginger, is endowed with medicinal properties apart from its nutritional and culinary values due to its numerous pharmacological actions (Stohs and Hartman, 2015). Ginger has anti-inflammatory (Grant and Lutz, 2000; Grzanna et al., 2005; Shimoda et al., 2009; Naderi et al., 2015), analgesic (Raji et al., 2002), anticancer (Surh et al., 1999), antidiabetic (Akhani et al., 2004), antioxidant (Shirin and Prakash, 2010; Mashhadi et al., 2013), anthelmintic (Lin et al., 2010), antiemetic (Blumenthal,
2003; Vutyavanich et al., 2001; Haniadka et al., 2013), immunomodulatory (Lumb, 1994; Chang et al., 1995; Carrasco et al., 2009; Mojani et al., 2014), antimicrobial (Omoya and Akharaiyi, 2011) and nephroprotective (Ajith et al., 2007) properties. Its antitrypanosomal action has also been reported (Kobo et al., 2014).

There has been deep focus on the antitrypanosmal properties of plants. Little work has been done to elucidate the efficacy of trypanocide/plant product combination. Therefore, there are few data in literature on the use of the established trypanocides in combination with natural products to enhance the efficacy of the trypanocides. It is our opinion that systematic search for natural products with trypanocidal and/or immunostimulant actions which can function in synergy with the aged trypanocides may be a cost effective and readily available tool in the treatment of trypanosomosis in the absence of new drugs.

\section{Materials and methods}

\section{Plant materials and extract preparation}

Fresh Zingiber officinale rhizomes were obtained in July, 2017 from a market in Ibadan, Southwestern Nigeria and were identified and authenticated at the herbarium of the Department of Botany, University of Ibadan, where voucher specimen (UIH 22484) was deposited for reference purposes. Following identification, $200 \mathrm{~g}$ of the rhizome were cleaned with water and crushed in a mortar and pestle. The mash was soaked in a percolator with analytical grade of methanol (Aldrich) at a ratio of 1:3 (plant:methanol) for $48 \mathrm{~h}$. Thereafter, the mixture was filtered and $60 \%$ of the initial volume of methanol was further added to the extract and allowed to stand for $24 \mathrm{~h}$. The extract was then concentrated in vacuo at $50{ }^{\circ} \mathrm{C}$ $55^{\circ} \mathrm{C}$. The dried extract was dissolved in Tween 80 for the study. 


Experimental animals,
trypanosomes and
procedure

Albino rats of Wistar strain, mixed sexes and weighing 120-150g were used in this study. They were obtained from the Experimental Animal house of the Faculty of Veterinary Medicine, University of Ibadan, and housed in standard rat cages with white plastic solid bottom and wire tops. Wood shavings were used as beddings. The cages were accommodated in a wellventilated fly proof house. Animals were humanely cared for in compliance with The Principles of Laboratory Animal Care. The institution's ethics committee approved and monitored the protocol. Animals were fed ad libitum with commercially formulated $8 \mathrm{~mm}$ pelletized mouse cubes (Ladokun Feeds, Ibadan). Water was provided ad libitum using plastic bottles equipped with sipper tubes. Excess feed and water were removed and replaced with fresh ones daily.

Animals were allowed to acclimatize for two weeks before the experiment commenced. Infection was with Trypanosoma brucei brucei (Strain TRIUN 0814) which was isolated from a pig at the University of Nigeria Veterinary Teaching Hospital, Nsukka, Nigeria, in 2014, and has since been maintained by serial passages in laboratory albino rats. Rats were infected by intraperitoneal infected with T. brucei brucei (1.6 x $10^{6}$ trypanosomes) as earlier described (Eghianruwa et al., 2009).

\section{Experimental design}

Seven groups of rats were constituted and treated as follows:

G1 $=400 \mathrm{mg} \cdot \mathrm{kg}^{-1}{ }^{1}$ ginger extract.

$\mathrm{G} 2=800 \mathrm{mg} \cdot \mathrm{kg}^{-1}{ }^{1}$ ginger extract.

GD1 $=400$ mg.kg- ${ }^{1}$ ginger extract + diminazene aceturate $3.5 \mathrm{mg} . \mathrm{kg}^{-}{ }^{1}$.

GD2 $=800 \mathrm{mg} \cdot \mathrm{kg}^{-1}$ ginger extract + diminazene aceturate $3.5 \mathrm{mg} . \mathrm{kg}{ }^{1}$.
$\mathrm{D}=$ infected and treated with diminazene aceturate $3.5 \mathrm{mg} . \mathrm{kg}^{1}{ }^{1}$ alone on day 5 pi.

C1= infected and treated with Tween 80 at $1 \mathrm{~mL} / \mathrm{kg}$ alone on day $5 \mathrm{pi}$.

$\mathrm{C} 2$ = uninfected control.

Each group contained 11 rats. On each of days 1 and 5 pi (post infection), three rats from each group were sacrificed while the surviving animals in groups GD1, GD2, GD3, and D were scarified on day 21 pi to obtain blood and organ samples. The doses of the extract were chosen from literature (Kobo et al., 2014).

\section{Treatment with ginger}

Groups G1 and G2 were treated daily per os from day 5 pi with the methanolic extract of ginger at graded doses of 400 mg.kg- ${ }^{1}$ and 800 mg.kg- ${ }^{1}$, respectively, while Groups GD1 and GD2 received a combination of single dose of diminazene aceturate intraperitoneally (3.5 mg.kg- ${ }^{1}$ ) on day 5 post infection with daily graded doses of $400 \mathrm{mg} \cdot \mathrm{kg}^{-1}$ and 800 mg.kg- ${ }^{1}$, respectively, of the methanolic extract of Zingiber officinale for 14 days beginning from day $5 \mathrm{pi}$.

\section{activity}

Assessment of therapeutic

The following parameters were evaluated: liver and spleen weights as percentages of body weight, survival rate as percent of surviving animals, parasitaemia and haematological indices (PCV, $\mathrm{Hb}$ and $\mathrm{Rbc}$ ).

Liver and spleen weights as well as haematological parameters were evaluated as earlier described (Eghianruwa et al., 2009) before infection, day 5 and day 21 pi. Parasitaemia was monitored on days 1 , 5, 9 pi and every other day after day 9 till day 21 pi using the method of Herbert and Lumsden, (1976).

\section{Statistical analysis}

Data obtained were expressed as mean \pm standard deviation (SD). The 
differences in the means of all parameters were analysed statistically with Instat ${ }^{\circledR}$ software (GraphPad Inc., USA) using one-way analysis of variance (ANOVA). Statistical estimates were made at confidence interval of $95 \%$. Probability values less or equal to 0.05 ( $p \leq 0.05)$ were considered significant.

\section{Results}

\section{Treatment effects on survivability}

Survival rates were $100 \%$ in all groups from day 1 to 6 pi. Deaths were recorded at different rates in all infected groups from day 6 pi. All animals in group C1 died by day 9 pi while those in G1, G2 died by day 10 pi [day 5 post treatment (pt)]. By day 21 pi the survival rates in the groups were $0 \%$ in C1, G1 and G2; $20 \%$ in D; $40 \%$ in GD2; $60 \%$ in GD1 and 100\% in C2 (Figure 1). Ginger alone did not protect the rats but a combination of ginger and diminazene gave better protection than diminazene alone. Increase in the dose of ginger from $400 \mathrm{mg} \cdot \mathrm{kg}^{-1}$ to $800 \mathrm{mg}^{-\mathrm{kg}}$ in the combination with diminazene resulted in lower number of survivors.

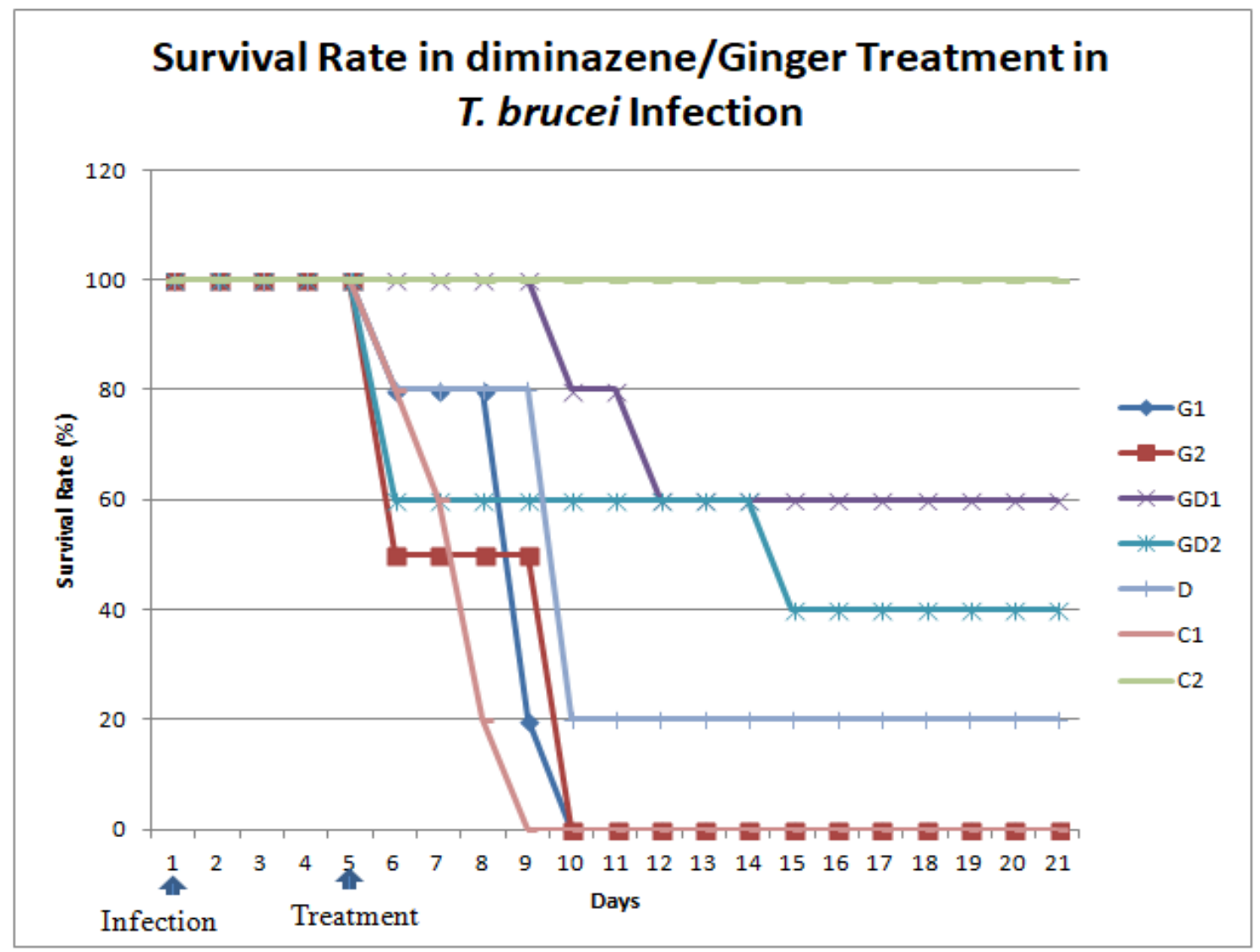

Figure 1. Survival rate chart of rats infected with T. brucei and treated with Diminazene with and without graded doses of methanolic extract of Zingiber officinale (ginger) rhizome. G1= $(400 \mathrm{mg} / \mathrm{kg}$ ginger extract $), \mathrm{G} \mathbf{2}=(800 \mathrm{mg} / \mathrm{kg}$ ginger extract $), \mathrm{G} 3=(1000 \mathrm{mg} / \mathrm{kg}$ ginger extract $), \mathrm{GD1}=(400$ $\mathrm{mg} / \mathrm{kg}$ ginger extract + Diminazene aceturate $3.5 \mathrm{mg} / \mathrm{kg}), \mathbf{G D 2}=(800 \mathrm{mg} / \mathrm{kg}$ ginger extract + Diminazene aceturate $3.5 \mathrm{mg} / \mathrm{kg}), \mathbf{G D} 3=(1000 \mathrm{mg} / \mathrm{kg}$ ginger extract + Diminazene aceturate 3.5 $\mathrm{mg} / \mathrm{kg}$ ), D = (infected and treated with Diminazene aceturate $3.5 \mathrm{mg} / \mathrm{kg}$ alone), $\mathbf{C 1}=$ (infected and treated with Tween $80 @ 1 \mathrm{~mL} / \mathrm{kg}$ alone), C2 = (uninfected control). 


\section{Parasitaemia}

Prepatent period was 3 days. Following treatment on day 5 pi, parasitaemia dropped to the lowest levels after 4 days in all groups except GD1 in which parasitemia experienced the greatest fluctuation (Figure 2). No treatment option was able to completely clear the parasites. By day 21 pi (day 16 pt), parasitemia levels were significantly $(\mathrm{P}<0.05)$ higher in D1 than GD1 and GD2 whereas there was no significant $(P>0.05)$ difference in the parasitemia levels in GD1 and GD2.

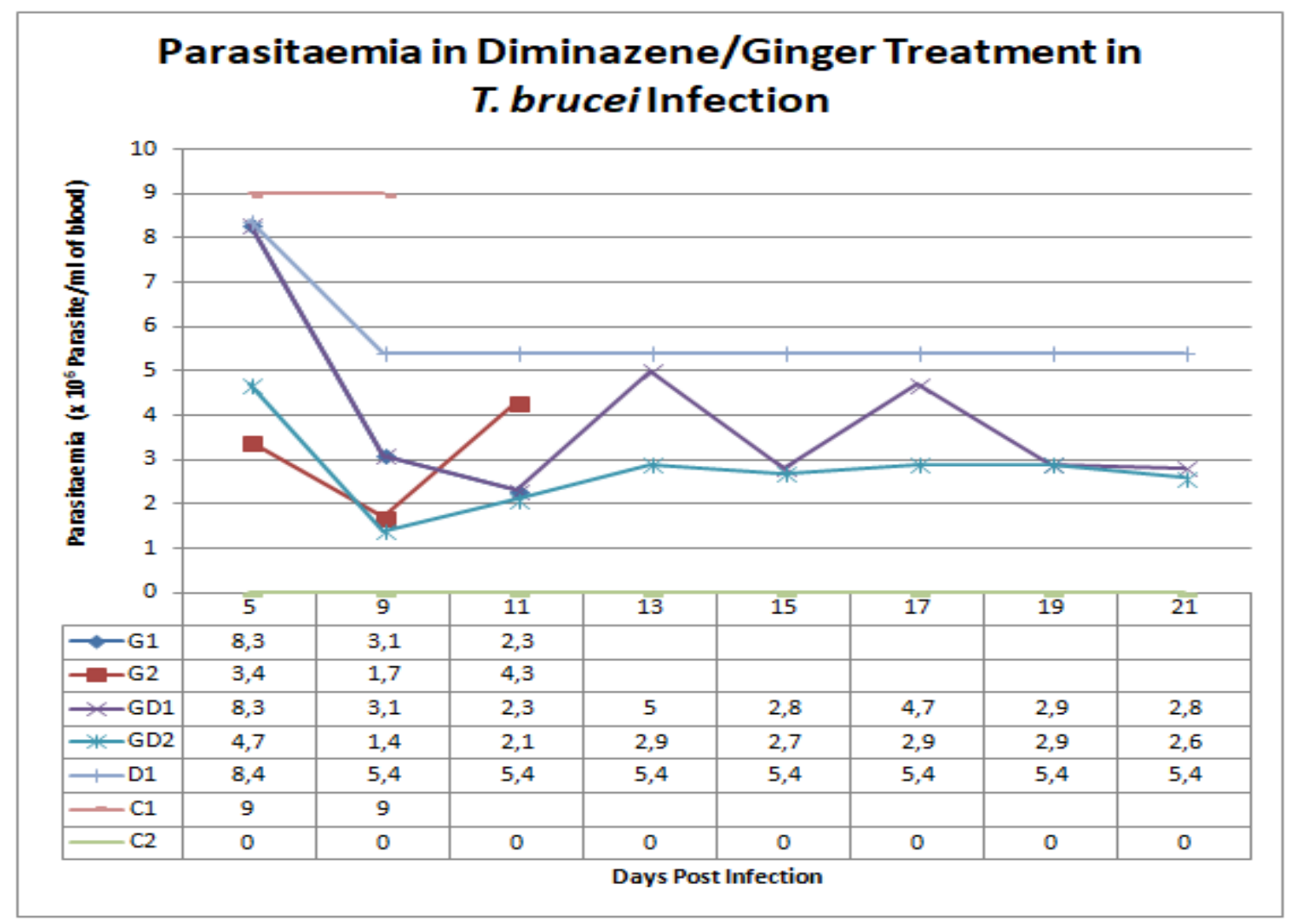

Figure 2. Parasitaemia levels in rats infected with T. brucei and treated with Diminazene alone and with graded doses of methanolic extract of Zingiber officinale (ginger) rhizome. G1= $(400 \mathrm{mg} / \mathrm{kg}$ ginger extract $), \mathrm{G} \mathbf{2}=(800 \mathrm{mg} / \mathrm{kg}$ ginger extract $), \mathrm{G} \mathbf{3}=(1000 \mathrm{mg} / \mathrm{kg}$ ginger extract $), \mathrm{GD} \mathbf{1}=(400$ $\mathrm{mg} / \mathrm{kg}$ ginger extract + Diminazene aceturate $3.5 \mathrm{mg} / \mathrm{kg}), \mathbf{G D 2}=(800 \mathrm{mg} / \mathrm{kg}$ ginger extract + Diminazene aceturate $3.5 \mathrm{mg} / \mathrm{kg}), \mathbf{G D} 3=(1000 \mathrm{mg} / \mathrm{kg}$ ginger extract + Diminazene aceturate 3.5 $\mathrm{mg} / \mathrm{kg}), \mathrm{D}=$ (infected and treated with Diminazene aceturate $3.5 \mathrm{mg} / \mathrm{kg}$ alone), $\mathbf{C 1}=$ (infected and treated with Tween $80 @ 1 \mathrm{ml} / \mathrm{kg}$ alone), $\mathrm{C} 2$ = (uninfected control).

\section{Treatment efects on haematological indices \\ Five days after the infection,} significantly $(\mathrm{P}<0.05)$ lower values of $\mathrm{PCV}, \mathrm{Hb}$ and RBC were recorded in all groups (Table 1). By day 21 pi (day 16 pt) the PCV value in GD1 was not significantly $(P>0.05)$ lower than normal but the $\mathrm{Rbc}$ value was not significantly $(P>0.05)$ lower than the value on day 5 pi (day 1 pt) but was significantly $(\mathrm{P}<0.05)$ lower than normal. The $\mathrm{Hb}$ value of the group was comparable to the value on day 5 pi. In contrast, the PCV, RBC and $\mathrm{Hb}$ values in GD2 and D on day 21 pi were significantly $(\mathrm{P}<0.05)$ less than normal but were comparable to one another. The values of these parameters remained within their normal ranges in group C2. 
Table 1. Haematological parameters in T. b. brucei infection treated with diminazene with or without grades doses of Zingiber officinale extract.

\begin{tabular}{|c|c|c|c|c|c|c|c|c|}
\hline $\begin{array}{l}\text { Days post } \\
\text { infection }\end{array}$ & Parameter & GI & G2 & GD1 & GD2 & D & C1 & $\mathrm{C} 2$ \\
\hline \multirow{3}{*}{1} & $\begin{array}{c}\text { PCV (\%) } \\
(\text { Mean } \pm \text { SD) }\end{array}$ & $53.5 \pm 1.90$ & $54.0 \pm 2.73$ & $51.2 \pm 2.20$ & $50.6 \pm 2.54$ & $55.0 \pm 2.51$ & $56.5 \pm 2.9$ & $54.0 \pm 2.54$ \\
\hline & $\begin{array}{l}\mathrm{Rhc}\left(\mathrm{x} 10^{6} / \mu \mathrm{l}\right. \\
\text { (Mean } \pm \mathrm{SD})\end{array}$ & $5.61 \pm 0.65$ & $5.45 \pm 0.45$ & $5.87 \pm 0.49$ & $4.91 \pm 0.71$ & $5.27 \pm 0.39$ & $5.30 \pm 0.20$ & $5.30 \pm 0.49$ \\
\hline & $\begin{array}{c}\mathrm{Hb}(\mathrm{g} / \mathrm{dl}) \\
(\text { Mean } \pm \mathrm{SD})\end{array}$ & $12.81 \pm 0.73$ & $11.89 \pm 0.65$ & $12.76 \pm 0.43$ & $11.8 \pm 0.73$ & $12.45 \pm 0.42$ & $11.91 \pm 0.17$ & $12.80 \pm 0.80$ \\
\hline \multirow{3}{*}{5} & $\begin{array}{c}\text { PCV (\%) } \\
\text { (Mean } \pm \text { SD) }\end{array}$ & $45.0 \pm 1.60$ & $37.0 \pm 4.02$ * & $42.01 \pm 3.63$ & $42.81 \pm 0.86 \times 5$ & $41.80 \pm 1.10$ & $42.23 \pm 1.65$ & $54.0 \pm 2.91$ \\
\hline & $\begin{array}{l}\mathrm{Rbc}\left(\mathrm{x} 10^{6} / \mu \mathrm{l}\right. \\
(\mathrm{Mean} \pm \mathrm{SD})\end{array}$ & $3.09 \pm 0.45 *$ & $3.17 \pm 0.48$ & $3.45 \pm 0.41^{5 *}$ & $3.75 \pm 0.56$ * & $3.16 \pm 0.41$ & $3.83 \pm 0.24$ & $5.22 \pm 0.32$ \\
\hline & $\begin{array}{c}\mathrm{Hb}(\mathrm{g} / \mathrm{dl}) \\
(\text { Mean } \pm \mathrm{SD})\end{array}$ & $8.55 \pm 1.21^{\star}$ & $8.23 \pm 1.12$ & $8.47 \pm 1.02$ & $8.32 \pm 1.41$ & $8.55 \pm 1.21$ & $8.25 \pm 1.21$ & $12.5 \pm 0.63$ \\
\hline \multirow{3}{*}{21} & $\begin{array}{c}\text { PCV (\%) } \\
\text { (Mean } \pm \text { SD) }\end{array}$ & NA & NA & $49.0 \pm 2.51^{*}$ & $33.3 \pm 1.00$ * * & $23.0 \pm 0.0 * 6$ & NA & $54.9 \pm 2.63$ \\
\hline & $\begin{array}{l}\mathrm{Rhc} \times 10^{6} / \mu \mathrm{l} \\
(\text { Mean } \pm \mathrm{SD})\end{array}$ & NA & NA & $3.57 \pm 0.32^{5 *}$ & $2.52 \pm 0.15$ * & $3.05 \pm 0.00$ & NA & $5.40 \pm 0.19$ \\
\hline & $\begin{array}{c}\mathrm{Hb}(\mathrm{g} / \mathrm{dl}) \\
(\text { Mean } \pm \mathrm{SD})\end{array}$ & NA & NA & $10.15 \pm 0.97$ & $9.48 \pm 0.23$ & $9.51 \pm 0.18$ & NA & $13.7 \pm 0.54$ \\
\hline
\end{tabular}

$\mathrm{a}=$ Significant difference $(\mathrm{P}<0.05)$ compared to the previous data in the same group; $\S=$ Significant difference $(\mathrm{P}<0.05)$ compared to $\mathrm{C} 2 ;^{*}=$ Significant difference $(\mathrm{P}<0.05)$ compared to $\mathrm{D} ; \mathbf{G 1}-(400$ $\mathrm{mg} / \mathrm{kg}$ Zingiber officinale extract), G2- (800 mg/kg Zingiber officinale extract), GB1- (400 mg/kg Zingiber officinale extract + Diminazene aceturate $3.5 \mathrm{mg} / \mathrm{kg}), \mathbf{G B 2}-(800 \mathrm{mg} / \mathrm{kg}$ Zingiber officinale extract + Diminazene aceturate $3.5 \mathrm{mg} / \mathrm{kg}), \mathrm{D}-(3.5 \mathrm{mg} / \mathrm{kg}$ diminazene $), \mathrm{C} 1$ - (1 mg/kg Teem 80); C2 (uninfected).

\section{Treatment effects on organ weights}

There were significant increases in liver and spleen weights on day 5 pi (Table 2). The weights of these organs were unchanged in C2 (uninfected). Sixteen days after treatment (21 days after infection) spleen weights in GD1 and GD2 were significantly (P < 0.05) lower than the corresponding values on the day of treatment (DOT; day 5pi). However, spleen weight was lower in group D on day 16 pt than on DOT but the difference was statistically insignificant ( $>>0.05$ ). The values of liver weight in GD, GD2 and D were significantly less $(\mathrm{P}<0.01)$ less than the values on DOT. Thus, liver weights never returned to their normal values in all treatment groups.

Table 2. Liver and spleen weights in $T$. $b$. brucei infected rats treated with diminazene with and without Zingiber officinale extract.

\begin{tabular}{|l|c|c|c|c|c|c|}
\hline \multirow{2}{*}{ Group } & \multicolumn{3}{|c|}{ Liver weight(\% BW) (Mean \pm SD) } & \multicolumn{2}{c|}{ Spleen weight (\% BW) (Mean \pm SD) } \\
\cline { 2 - 7 } & \multicolumn{3}{|c|}{ Days post infection } & \multicolumn{3}{c|}{ Days post infection } \\
\cline { 2 - 7 } & Day 1 & Day 5 (D0T) & Day 21 & Day 1 & Day 5 (D0T) & Day 21 \\
\hline C1 & $3.45 \pm 0.23$ & $5.34 \pm 0.44 *$ & NA & $0.36 \pm 0.08$ & $2.98 \pm 0.61 *$ & NA \\
\hline C2 (Uninfected) & $3.55 \pm 0.33$ & $3.27 \pm 0.35$ & $3.42 \pm 0.32$ & $0.34 \pm 0.08$ & $0.31 \pm 0.027$ & $0.33 \pm 0.03$ \\
\hline G1 & $3.49 \pm 0.21$ & $4.96 \pm 0.66 *$ & NA & $0.32 \pm 0.06$ & $2.77 \pm 0.64 *$ & NA \\
\hline G2 & $3.61 \pm 0.40$ & $5.05 \pm 0.81 *$ & NA & $0.29 \pm 0.09$ & $2.85 \pm 0.56 *$ & NA \\
\hline D & $3.58 \pm 0.42$ & $5.72 \pm 0.92 *$ & $4.36 \pm 0.08^{\phi}$ & $0.33 \pm 0.01$ & $2.98 \pm 0.61 *$ & $2.00 \pm 0.10$ \\
\hline GD1 & $3.47 \pm 0.11$ & $5.24 \pm 0.26 *$ & $4.01 \pm 0.07^{\phi}$ & $0.35 \pm 0.05$ & $2.98 \pm 0.61 *$ & $1.13 \pm 0.43^{*}$ \\
\hline GD2 & $3.38 \pm 0.32$ & $5.22 \pm 1.13 *$ & $4.63 \pm 0.44^{\phi}$ & $0.33 \pm 0.07$ & $2.98 \pm 0.61 *$ & $1.01 \pm 0.01^{*}$ \\
\hline
\end{tabular}

DOT $=$ Day of treatment; NA $=$ Not applicable because there were no survivors; $*$ significantly different from values on day $1(\mathrm{P}<0.05)$; ${ }^{*}$ Significantly different from values on day $5 \mathrm{pi} ;{ }^{\phi}$ Significantly different from day 5 pi ( $<$ < 0.05); G1- (400 mg/kg Zingiber officinale extract), G2- (800 $\mathrm{mg} / \mathrm{kg}$ Zingiber officinale extract), GB1- (400 mg/kg Zingiber officinale extract + Diminazene aceturate $3.5 \mathrm{mg} / \mathrm{kg}$ ), GB2- (800 mg/kg Zingiber officinale extract + Diminazene aceturate 3.5 $\mathrm{mg} / \mathrm{kg}$ ), D - (3.5 mg/kg diminazene), C1 - (1 mg/kg Teem 80); C2 (uninfected). 


\section{Discussion}

Results from this study revealed improved survival rate following the concurrent administration of oral daily doses of $400 \mathrm{mg} \cdot \mathrm{kg}^{-1}$ and $800 \mathrm{mg} \cdot \mathrm{kg}^{-1}$ of ginger for 14 days and $3.5 \mathrm{mg} \cdot \mathrm{kg}^{-1}$ diminazene aceturate intraperitoneally. Ascorbate and dimethyl sulphoxide (DMSO) have also been reported to enhance survival rate in diminazene treated rats infected with $T$. brucei (Eghianruwa, 2012a). These findings were attributed to the antioxidant properties of ascorbate and DMSO. There was a strong correlation between the haematological and parasitaemia values obtained in GD2 with survival rate. The survival rate in this group was $40 \%$ compared to $60 \%$ (GD1) when a lower dose of ginger was combined with diminazene. The observation is that increase in the dose of ginger resulted in reduced boost of diminazene effect. The reason(s) for this is not known. Similar observation was made with ascorbate. Increase in the dose of ascorbate from $200 \mathrm{mg} \cdot \mathrm{kg}^{-1}$ to $400 \mathrm{mg} \cdot \mathrm{kg}^{-1}$ resulted in reduced rate of recovery of the liver (Eghianruwa et al., 2009). This observation was thought to be associated with the report that certain antioxidants become prooxidants at high doses. This has been documented in the case of ascorbate and tocopherol (Benedich and Olson, 1989; Yu, 1994). It is not known whether this is the case with ginger even though it has been reported as having antioxidant properties (Shirin and Prakash, 2010). Eghianruwa and Anika (2012b) also observed that increase in the dose of dimethylsulfoxide from $1 \mathrm{g.kg}{ }^{-1}$ to $2{\mathrm{~g} . \mathrm{kg}^{-1}}^{-1}$ resulted in toxicity and reduced diminazene effect.

At the end of the experiments parsitemia was lower in groups that received ginger concurrently with diminazene than in groups treated with diminazene alone. This may be attributed to the relative resistance of $T$ brucei to diminazene. Hence, diminazene is used on the field at higher doses in T. brucei infections (Shiferaw et al., 2015). However, the enhanced survival rate observed with concurrent administration of ginger with sub therapeutic doses of diminazene is indicative of the fact that better survival rate could be achieved when diminazene dose is increased.

The reduced haematological indices resulting from $T$. brucei infection has been severally reported (Kaikabo and Salako, 2006; Toma et al., 2008; Eghianruwa and Anika, 2011; Faremi and Ekanem, 2011). However, no treatment protocol returned the haematological indices to normal by day 21 pi or 16 days after initiation of treatment. Similarly, liver and spleen weight never return to normal under any treatment protocol. This situation may be related to the observation in this study that no treatment effectively controlled parasitemia. Hence, pathological damages caused by the parasites were continuous throughout the observation period.

Administration of ginger alone did not cure infected rats in spite of reports of its trypanocidal action (Kobo et al., 2014). Survival rates in groups that received ginger alone were zero percent even at a dose as high as 800 mg.kg- ${ }^{1}$. The observation from this study is not in consonant with that of (Kobo et al., 2014) who reported that administration of methanolic extract of Z. officinale reduced the level of parasitemia, increased body weight and survival time of mice infected with T. brucei brucei. Although parasitemia was lowest in the ginger groups in this study, the animals died by day $6 \mathrm{pt}$.

\section{Conclusion}

Most reports on antitrypanosomal actions in plants are from preliminary studies where plants were evaluated singly. This study has evaluated the influence of a plant product on diminazene efficacy. The result on improved survival is encouraging but more work needs to be 
done to assess the mechanism by which ginger enhances survival rates in diminazene treated $T$. brucei infection.

\section{Conflict of interests}

The authors declare that there are no conflicts of interest.

\section{References}

Adeiza, A. A.; Makeri, H. K.; Mohammed, M. Comparative in vitro trypanocidal activities of water and methanol extracts of three parts of Khaya senegalensis on Trypanosoma evansi. Journal of Medicinal Plants Research, v. 4, no. 14, p. 1365-1369, 2010. https://doi.org/ 10.5897/JMPR10.058

Ajith, T. A.; Nivitha, V.; Usha, S. Zingiber officinale Roscoe alone and in combination with $\alpha$-tocopherol protect the kidney against cisplatin-induced acute renal failure. Food Chemical Toxicology, v. 45, no. 6, p. 921-927, 2007. https://doi.org/10.1016/ j.fct.2006.11.014

Akhani, S. P.; Vishwakarma, S. L.; Goyal, R. K.; Anti-diabetic activity of Zingiber officinale in streptozotocin-induced type I diabetic rats. Jounal of Pharmacy and Pharmacology, v. 56 , p. $101-105,2004$. https://doi.org/ $10.1211 / 0022357022403$

Benedich, A.; Olson, J. A. Biological action of carotenoids. The FASEB Jounal, v. 3, p. 19271932, 1989. https://doi.org/10.1096/fasebj. 3.8.2656356

Blumenthal, M. Ginger as an antiemetic during pregnancy. Alternative Therapies in Health and Medicine, v. 9, p. 19-21, 2003.

Carrasco, F. R.; Schmidt, G.; Romero, A. L.; Sartoretto, J. L.; Caparroz-Assef, S. M; Bersani-Amado, C. A.; Cuman, R. K. Immunomodulatory activity of Zingiber officinale Roscoe, Salvia officinalis L. and Syzygium aromaticum L. essential oils: evidence for humor- and cell-mediated responses. Jounal of Pharmacy and Pharmacology, v. 61, p. 961-967, 2009. https://doi.org/10.1211/jpp.61.07.0017

Chang, C. P.; Chang, J.-Y.; Wang, F.-Y.; Chang, J.-G. The effect of Chinese medicinal herb Zingiberis rhizoma extract on cytokine secretion by human peripheral blood mononuclear cells. Journal of Ethnopharmacology, v. 48, p.13-19, 1995. https://doi.org/10.1016/0378-8741(95) 01275-I

Eghianruwa, K. I.; Anika, S. M. Effects of dimethyl sulphoxide and ascorbic acid pretreatment on prepatent period, parasitemia, hematology and tissue pathology in rats infected with $T$. brucei. Tropical Veterinarian, v. 28, p. 13-20, 2010.

Eghianruwa, K. I.; Anika, S. M. The effects of selenium and tocopherol supplementation on the efficacy of diminazene aceturate in reversing $T$. brucei-induced anemia in rats. Veterinarski Arhiv, v. 81, p. 647-656, 2011. Available from: <https://hrcak.srce.hr/ index.php?show=clanak\&id_clanak_jezik=10 8648>. Accessed on: Dec. 23, 2017.

Eghianruwa, K. I. Effect of supplemental antioxidants, vitamin $\mathrm{C}$ and DMSO on weight gain and survivability in T. brucei infected and diminazene treated rats. Veterinarski Arhiv, v. 82, p. 519-529, 2012a. <https://hrcak.srce.hr/index.php?show=clan ak\&id_clanak_jezik=128527>. Accessed on: Dec. 23, 2017.

Eghianruwa, K. I.; Anika, S. M. Effects of DMSO on diminazene efficacy in experimental murine T. brucei infection. International Journal of Animal and Veterinary Advances, v. 4, p. 93-98, 2012b. Available from: <http://maxwellsci.com/ print/ijava/v4-93-98.pdf>. Accessed on: Dec. 23, 2017.

Eghianruwa, K. I.; Anika, S. M.; Akpavie, S. 0. Efficacy of diminazene with and without ascorbic acid supplementation in T. brucei infected rats. Tropical Veterinarian, v. 27, p. 20-36, 2009.

Faremi, A.Y.; Ekanem, J. T. Haematological parameters and enzyme studies in Trypanosoma brucei-infected rats reared on Nigella sativa oil-based diet. Asian Journal of Biochemistry, v. 6, p. 90-97, 2011. https://doi.org/10.3923/ajb.2011.90.97

Grant, K. L.; Lutz, R. B. Ginger. American Journal of Health-System Pharmacy, v. 57, p. 945-947, 2000.

Grzanna, R.; Lindmark, L.; Frondoza, C. Ginger: An herbal medicinal product with broad anti-inflammatory action. Journal of Medical Food, v. 8, p. 125-132, 2005. https://doi.org/10.1089/jmf.2005.8.125

Haniadka, R.; Saldanha, E.; Sunita, V.; Palatty, P. L.; Fayad, R.; Baliga, M. S. A review of the gastroprotective effects of ginger (Zingiber officinale Roscoe). Food \& Function, v. 4, 
p. 845-855, 2013. https://doi.org/10.1039/ c3fo30337c

ILRI - International Livestock Research Institute. Trypanosomiasis. Available from <http://www.ilri.org/infoserv/webpub/fulldo cs/ilrad87/epidemiology.htm>. Accessed on: Jul. 28, 2008.

Kaikabo, A. A.; Salako, M. A. Effects of vitamin E supplementation on anemia and tissue pathology in rats infected with Trypanosoma brucei (Federe strain). Tropical Veterinarian, v. 24, p. 46-51, 2006.

Kobo, P. I.; Erin, P. J.; Suleiman, M. M.; Aliyu, H.; Tauheed, M.; Muftau, S.; Mamman, M. Antitrypanosomal effect of methanolic extract of Zingiber officinale (ginger) on Trypanosoma brucei brucei-infected Wistar mice. Veterinary World, v. 7, p. 770-775, 2014. Available from: <http://www.veterinaryworld.org/Vol.7/Oct ober-2014/3.pdf>. Accessed on: Dec. 23, 2017.

Lin, R. J.; Chen, C. Y.; Chung, L. Y.; Yen, C. M. Larvicidal activities of ginger (Zingiber officinale) against Angiostrongylus cantonensis. Acta Tropica, v. 115, p. 69-76, 2010. https://doi.org/10.1016/j.actatropica. 2009.12.007

Lumb, A. B. Effect of dried ginger on human platelet function. Journal of Thrombosis and Haemostasis, v. 71, p. 110-111, 1994.

Mashhadi, N. S.; Ghiasvand, R.; Askari, G.; Hariri, M.; Darvishi, L.; Mofid, M. R. Antioxidative and anti-inflammatory effects of ginger in health and physical activity: Review of current evidence. International Journal of Preventive Medicine, v. 4, suppl. 1, p.S1-S7, 2013. Available from: <http://ijpm.mui.ac.ir/index.php/ijpm/articl e/view/1117>. Accessed on: Dec. 23, 2017.

Mojani, M. S.; Rahmat, A.; Ramasamy, R. Ginger (Zingiber officinale Roscoe) immunenutritional behavior: An overview. Nutrition \& Food Science, v. 1, suppl. 1, p. 189-190, 2014.

Naderi, Z.; Mozaffari-Khosravi, H.; Dehghan, A.; Nadjarzadeh, A.; Huseini, H. F. Effect of ginger powder supplementation on nitric oxide and C-reactive protein in elderly knee osteoarthritis patients: A 12-week doubleblind randomized placebo-controlled clinical trial. Journal of Traditional and Complementary Medicine, v 28, p. 199-203, 2015. https://doi.org/10.1016/j.jtcme.2014. 12.007
Ogbadoyi, E. O.; Garba, M. H.; Kabiru, A. Y.; Mann, A.; Okogun, J. Therapeutic evaluation of Acacia nilotica (Linn) stem bark extract in experimental African trypanosomiasis. International Journal of Applied Research in Natural Products, v. 4, p. 11-18, 2011. Available from: <http://www.ijarnp.org/ index.php/ijarnp/article/view/6/6>.

Accessed on: Dec. 23, 2017.

Omoja, V. U.; Anaga, A. O.; Obidike, I. R.; Ihedioha, T. E.; Umeakuana, P. U.; Mhomga, L. I.; Asuzu, I. U.; Anika, S. M. The effects of combination of methanolic leaf extract of Azadirachta indica and diminazene diaceturate in the treatment of experimental Trypanosoma brucei brucei infection in rats. Asian Pacific Journal of Tropical Medicine, v. 4, no. 5, p. 337-341, 2011. https://doi.org/ 10.1016/S1995-7645(11) 60099-0

Omoya, F. 0; Akharaiyi, F. C. Mixture of honey and ginger extract for antibacterial assessment on some clinical isolates. International Journal on Pharmaceutical and Biomedical Research, v. 2, no. 1, p.39-47, 2011. Availabe from: <http://www.kejapub.com/ijpbr/docs/IJPB

R11-02-01-07.pdf>. Accessed on: Dec. 23, 2017.

Onyiah, J. A. African animal Trypanosomiasis: An overview of the current status in Nigeria. Tropical Veterinarian, v. 15, p. 111-116, 1997.

Raji, Y.; Udoh, U.S.; Oluwadara, 0. 0; Akinsomisoye, O. S.; Awobajo, 0.; Adeshoga, K. Anti-inflammatory and analgesic properties of the rhizome extract of Zingiber officinale. African Journal of Biomedical Research, v. 5, no. 3, p. 121-124, 2002. https://doi.org/10.4314/ajbr.v5i3.53999

Shiferaw, S.; Muktar, Y.; Belina, D. A review on trypanocidal drug resistance in Ethiopia. Journal of Parasitology and Vector Biology, v. 7, p. 58-66, 2015. Available from: <http://www.academicjournals.org/article/ article1429095115_Shiferaw et al.pdf>. Accessed on: Dec. 23, 2017.

Shimoda, H.; Shan, S. J; Tanaka, J; Seki, A; Seo, J. W.; Kasajima, N.; Tamura, S.; Ke, Y.; Murakami, N. Anti-inflammatory properties of red ginger (Zingiber officinale var. Rubra) extract and suppression of nitric oxide production by its constituents. Journal of Medical Food, v. 13, no. 1, p. 156-162, 2010. https://doi.org/10.1089/jmf.2009.1084 
Shirin, A.P. R.; Prakash, J. Chemical composition and antioxidant properties of ginger root (Zingiber officinale). Journal of Medicinal Plants Research, v. 4, no. 24, p. 2674-2679, 2010. Available from: <http://www.academicjournals.org/article/ article1380710823_Shirin and Jamuna.pdf>. Accessed on: Dec. 23, 2017.

Stohs, S. J.; Hartman, M. J. Review of the safety and efficacy of Moringa oleifera. Phytotherapy Research, v. 29, p. 796-804, 2015. https://doi.org/10.1002/ptr.5325

Surh, Y. J.; Park, K. K.; Chun, K. S.; Lee, L. J.; Lee, E.; Lee, S. S. Anti-tumor-promoting activities of selected pungent phenolic substances present in ginger. Journal of Environmental Pathology, Toxicology and Oncology, v. 18, p. 131-139, 1999.

Toma, I.; Shinggu, D. Y.; Ezekiel, W.; Barminas, J. T. Effect of intraperitoneal administration of vitamin $\mathrm{C}$ (ascorbic acid) on anemia in experimental Trypanosoma congolense infected rabbits. African Journal of Pure Applied Chemistry, v. 2, p. 37-40, 2008.

Vutyavanich, T.; Kraisarin, T.; Ruangsri, R. Ginger for nausea and vomiting in pregnancy: randomized, double-masked, placebocontrolled trial. Obstetrics \& Gynecology, v. 97, no. 4, p. 577-582, 2001. Available from: <https://journals.lww.com/greenjournal/Ful ltext/2001/04000/Ginger_for_Nausea_and_V omiting_in_Pregnancy_.17.aspx>. Accessed on: Dec. 23, 2017.

Yu, B. P. Cellular defenses against damage from reactive oxygen species. Physiological Reviews, v. 74, no. 1, p. 139-162, 1994. https://doi.org/10.1152/physrev.1994.74.1. 139

License information: This is an open-access article distributed under the terms of the Creative Commons Attribution License, which permits unrestricted use, distribution, and reproduction in any medium, provided the original work is properly cited. 